\title{
CFRP strengthening of prefabricated timber panel walls
}

\author{
M. Premrov \& P. Dobrila \\ University of Maribor, Faculty of Civil Engineering, Slovenia
}

\begin{abstract}
This paper provides an experimental analysis of timber-framed walls, coated with carbon fibre-reinforced polymers (CFRP) strengthened fibre-plaster boards, usually used as main bearing capacity elements in the construction of prefabricated timber structures. The tensile strength of the boards is lower than the compressive one and essentially lower than the strength of the timber frame, therefore it is convenient to strengthen boards in their tensile diagonal direction with high-strength materials in order to gain a higher capacity. It has been shown that the inclusion of CFRP diagonal strip reinforcement on the load-carrying capacity can be quite high and that it is maximized when the carbon strips are connected to the timber frame. On the other hand, the ductility itself was not significantly improved. The test samples proved an important distinction in behaviour in timber frame-fibreboard connecting area, dependant on the boundary conditions between inserted CFRP strips and timber frame.

Keywords: timber, frame walls, CFRP, fibre-plaster boards, experiments.
\end{abstract}

\section{Introduction}

There is an increasing tendency worldwide toward building multi-level prefabricated timber structures with timber-framed walls as the main bearing capacity elements. Their load-carrying capacity becomes critical, especially when taller structures are subjected to heavy horizontal forces, particulary with structures located in seismic and windy areas. In this case it is sometimes necessary to reinforce the walls. The treated wall is a composite element consisting of framed panels made from sheets of board-material fixed by mechanical fasteners to one or both sides of the timber frame (Figure 1). There are many types of panel products available which may have some structural 
capacity such as wood-based materials (plywood, oriented strand board, hardboard, particleboard, etc.) or plaster boards and, more recently fibre-plaster boards. In the following analysis we limited our attention to the fibre-plaster boards (FPB), recently the most frequently used in Central Europe. One of the most important reasons for an increased application of these types of gypsum products is their relatively good fire protection. Additionally, gypsum is a healthy natural material and is consequently particularly desired for residential buildings.

In structural analysis panel walls for design purposes can be regarded separately as vertical cantilever beams with the horizontal force $\left(F_{H}=F_{H, t o t} / n\right)$ acting at the top (Figure 1). Considered supports approximate an influence of neighbouring panel walls and assure an elastic-clamped boundary condition for the treated wall (Faherty and Williamson [1] or Eurocode 5 [2]).

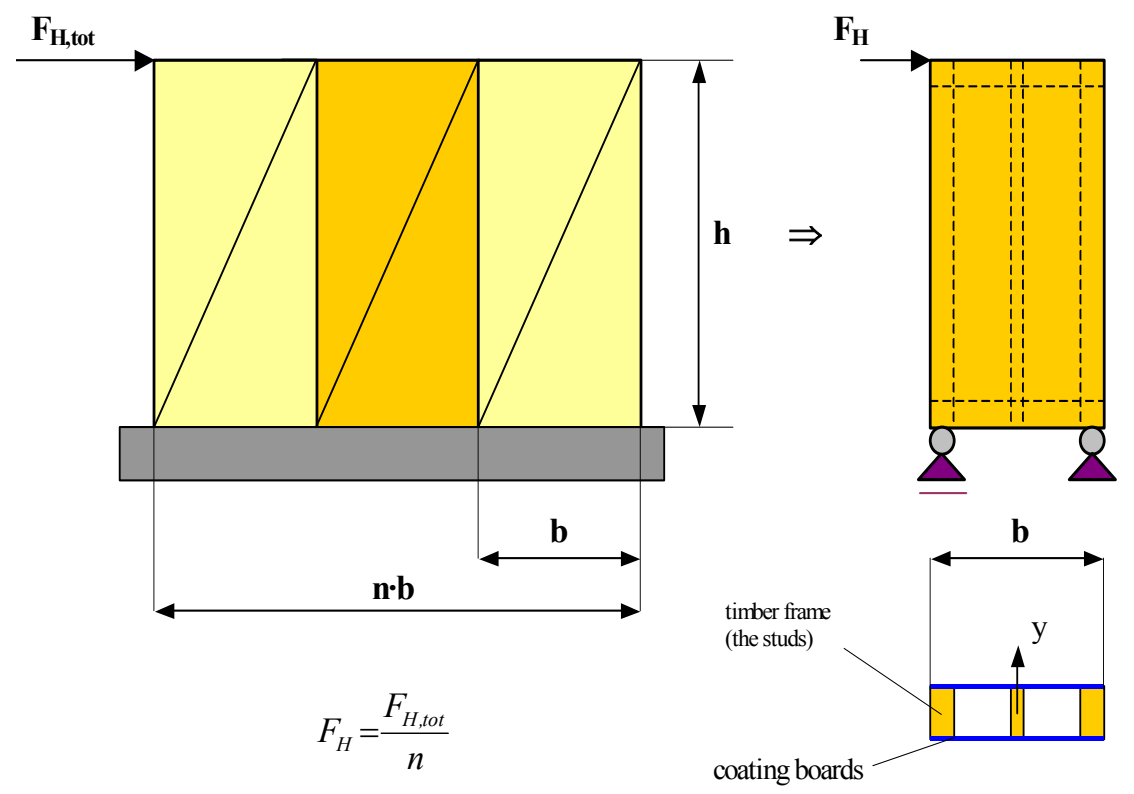

Figure 1: Static design and cross section of the treated panel wall.

\section{Design models}

\subsection{Shear model}

Many design models have been proposed in order to analyse and predict the behaviour of wood-based shear walls and diaphragms subjected to lateral loads. Källsner [3] and Äkerlund [4] proposed an agreeable approach to determine the load-carrying capacity of the wall unit, based on the following key assumptions:

- behaviour of the joints between the sheet and the frame members is assumed to be linear-elastic until failure, 
- the frame members and the sheets are assumed to be rigid and hinged to each other.

The influence of shear deformations in the fibreboard can be additionally estimated by introducing the shear angle. Additionally, two models are presented based on the assumption that the load-displacement relation of fasteners is completely plastic. Källsner and Lam [5] presented the walls load-carrying capacity as a function of fasteners spacing along the upper horizontal timber member assuming constant fastener spacing along all timber members.

Two simplified computational methods are given in the final draft of Eurocode 5 [2] in order to determine the load-carrying capacity of the wall diaphragm. The first simplified analysis - Method $A$, is identical to the "Lower bound plastic method", presented by Källsner and Lam [5]. This method defines the wall's shear resistance $\left(\mathrm{F}_{\mathrm{v}, \mathrm{d}}\right)$ as a sum of all the fasteners' shear resistances along the loaded edges in the form of:

$$
F_{v, d}=\sum F_{f, R d} \cdot \frac{b_{i}}{s} \cdot c_{i}
$$

$\mathrm{F}_{\mathrm{f}, \mathrm{Rd}}$.... lateral design capacity per fastener,

$b_{i} \ldots . . \quad$ wall panel width,

s ..... fastener spacing,

$$
c_{i}=\left\{\begin{array}{l}
1 \quad \text { for } b_{i} \geq b_{0} \\
\frac{b_{i}}{b_{0}} \text { for } b_{i} \leq b_{0}
\end{array} \quad \text { where } b_{0}=h / 2\right.
$$

This is only an approximated and simplified definition, which can be applicable for wood-based panels where the strength is relatively high and the elements tend to fail because of fastener yielding.

The second simplified analysis - Method $B$ is applicable to walls made from sheets of wood-based panel products only, fastened to a timber frame. The fastening of the sheets to the timber frame should either be by nails or screws, and the fasteners should be equally spaced around the perimeter of the sheet. According to Method $A$ the sheathing material factor $\left(k_{n}\right)$, the fastener spacing factor $\left(\mathrm{k}_{\mathrm{s}}\right)$, the vertical load factor $\left(\mathrm{k}_{\mathrm{i}, \mathrm{q}}\right)$ and the dimension factors for the panel $\left(\mathrm{k}_{\mathrm{d}}\right)$ are included in the design procedure in the form of:

$$
F_{v, d}=\sum F_{f, R d} \cdot \frac{b_{i}}{s_{0}} \cdot c_{i} \cdot k_{d} \cdot k_{i, q} \cdot k_{s} \cdot k_{n} ; \quad s_{0}=\frac{9700 \cdot d}{\rho_{k}}
$$

d ... fastener diameter, $\rho_{\mathrm{k}} \ldots$ characteristic density of the timber frame

\subsection{Composite model}

All the above mentioned methods are usually unsuitable for treated walls sheathed with fibre-plaster boards (FPB). The main assumptions do not exactly coincide with the real state of FPB, in which the tensile strength is evidently 
lower than the compressive one. Consequently, cracks in a tensile zone usually appear under heavy horizontal loads before stresses on the fasteners reach their yielding point, and the fibreboards do not behave usually as rigid elements (Dobrila and Premrov [6]). However, by employing FPB as a coating material, a horizontal load shifts a part of the force over the mechanical fasteners to the fibreboard and the wall acts like a deep beam. Distribution of the horizontal force by composite treatment of the element depends on the proportion of stiffness. The effective bending stiffness $\left(\mathrm{EI}_{\mathrm{y}}\right)_{\mathrm{eff}}$ of mechanically jointed beams taken from Eurocode 5 [2] can be written in the form of:

$$
\begin{aligned}
& \left(E I_{y}\right)_{\text {eff }}=\sum_{i=1}^{n} E_{i} \cdot\left(I_{y i}+\gamma_{y i} \cdot A_{i} \cdot a_{i}^{2}\right)= \\
& =\sum_{i=1}^{n_{\text {timber. }}}\left(E_{i} \cdot I_{y i}+E_{i} \cdot \gamma_{y i} \cdot A_{i} \cdot a_{i}^{2}\right)_{\text {timber }}+\sum_{j=1}^{n_{\text {board }}}\left(E_{i} \cdot I_{y i}\right)_{\text {board }}
\end{aligned}
$$

where $\mathrm{n}$ is the total number of elements in the considered cross-section and $\mathrm{a}_{\mathrm{i}}$ is $\mathrm{a}$ distance between global $y$-axis of the whole cross-section and local $y_{\mathrm{i}}$-axis of the i-th element with a cross-section $A_{i}$ (see Figure 2). It is evident that the force distribution in this case strongly depends on the stiffness coefficient of the connecting area $\left(\gamma_{\mathrm{y}}\right)$, which mostly depends on the fasteners slip modulus $\left(\mathrm{K}_{\mathrm{ser}}\right)$ and fasteners disposition, as well as on the type of the connection. An experimental analysis on the influence of fasteners spacing on behaviour of the treated walls can be found in [6].

\section{Strengthening of fibre-plaster boards}

As described, the FPB are usually a weaker part of the presented composite system, because their tensile strength is evidently smaller than the wood strength of all members in the timber frame. Thus, especially in multi-level buildings located in seismic or windy areas, cracks in FPB usually appear. In these cases the FPB lose their stiffness and therefore their resistance should not be considered at all. Stresses in the timber frame under a horizontal loads are usually not critical. There are several possibilities to reinforce panel walls in order to avoid cracks in FPB:

- by using additional boards. The boards are usually doubled:

- symmetrically (on both sides of a timber frame),

- non-symmetrically (on one side of a timber frame),

- by reinforcing boards with steel diagonals,

- by reinforcing boards with carbon or high-strength synthetic fibres.

\subsection{Strengthening with additional FPB}

In [6] we presented the first possibility experimentally using additional FPB, which gave higher elasticity of elements, whilst bearing capacity and especially ductility were not improved in the desired range. 


\subsection{Strengthening with diagonal steel strips}

With the intention to improve the resistance and especially the ductility of the walls it is more convenient to insert diagonal steel strips, which have to be fixed to the timber frame. In this case only a part of the horizontal force is shifted from boards over the tensile steel diagonal to the timber frame after the appearance of the first crack in the tensile zone of FPB (see [6]). An enlarged effective crosssection of FPB $\left(\mathrm{A}^{*}{ }_{1 \mathrm{~b}}\right)$ can approximately be computed considering the compatibility conditions between the actual reinforced and fictitious unreinforced element. The computational procedure is described in details in Premrov and Dobrila [7] and will not be presented here. With regard to the fictive enlarged cross-section of FPB we proposed two approximate analytical models using either fictitious thickness $\left(\mathrm{t}^{*}\right)$ or fictitious width $\left(\mathrm{b}^{*}\right)$ of fibreboards:

$$
\begin{aligned}
& t^{*}=\frac{A_{1 b}^{*}}{b}=t+\frac{1}{\chi} \cdot \frac{E_{s}}{G_{b}} \cdot \sin ^{2} \alpha \cdot \cos \alpha \cdot A_{1 s, 0} \cdot \frac{1}{b} \\
& b^{*}=\frac{A_{1 b}^{*}}{t}=b+\frac{1}{\chi} \cdot \frac{E_{s}}{G_{b}} \cdot \sin ^{2} \alpha \cdot \cos \alpha \cdot A_{1 s, 0} \cdot \frac{1}{t}
\end{aligned}
$$

In the above equations $\alpha$ represents the angle of inserted steel diagonals with the net area $\left(\mathrm{A}_{1 \mathrm{~s}, 0}\right)$. A non-dimensional coefficient $\chi$ is shear cross-section coefficient defined as a proportion between the shear and actual cross-sectional area of the FPB with the shear modulus $\left(G_{b}\right)$. Alongside the steel diagonals' influence these models enable simultaneous consideration of the fasteners' flexibility between the board and the timber frame and any appearing cracks in the tensile area of the FPB. Un-reinforced panels can be computed using actual dimensions of the FPB. Numerical results presented in [7] on diagonally steel reinforced elements show good agreement with measurements performed on the test samples.

\subsection{Strengthening with diagonal CFRP strips}

As the tensile strength of FPB is obviously lower than the compressive strength and corresponding capacity of timber frame, the treated elements tend to fail because the cracks are forming in the tensile area of the FPB, therefore this tensile area could be reinforced with high-strength materials. This strengthening concept is such that the composites would contribute to tensile capacity when the tensile strength of FPB is exceeded. No FRP applications on the treated fibreplaster boards were found in the literature.

\section{Test experiment: strengthening with CFRP strips}

\subsection{Test configuration}

Three sample groups from total of nine test samples were tested in order to carry out appropriate experimental research on the influence of CFRP strengthened 
walls. All test groups consisted of three walls of actual dimensions $\mathrm{h}=263.5 \mathrm{~cm}$ and $b=125 \mathrm{~cm}$. The cross-section presented in Figure 2 was composed of timber studs $(2 \times 9 \times 9 \mathrm{~cm}$ and $1 \times 4.4 \times 9 \mathrm{~cm})$, timber girders $(2 \times 8 \times 9 \mathrm{~cm})$ and Knauf fibreplaster boards (Knauf [8]) of thickness $t=15 \mathrm{~mm}$. They were fixed to the timber frame using staples of $\Phi 1.53 \mathrm{~mm}$ at an average spacing of $\mathrm{s}=75 \mathrm{~mm}$.

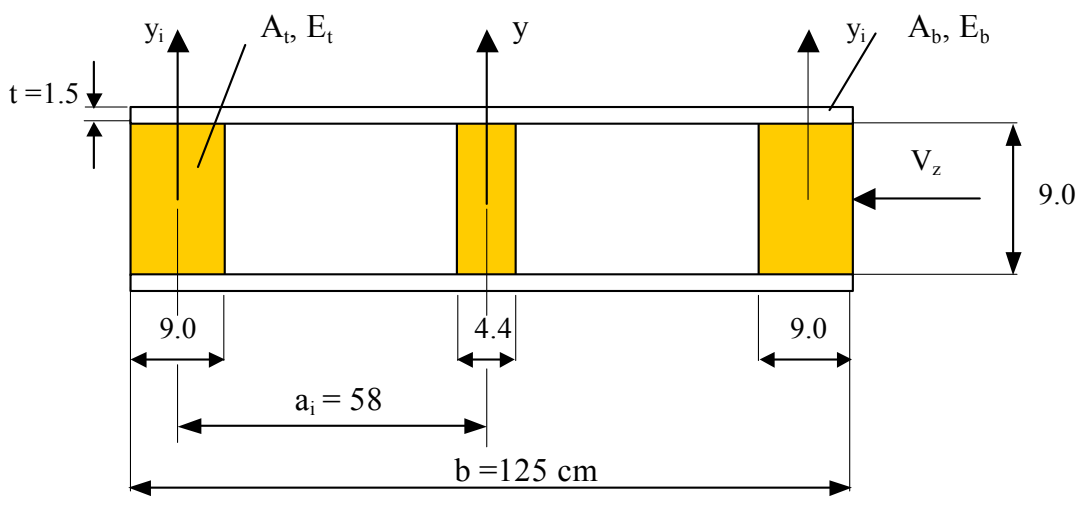

Figure 2: $\quad$ Cross-section of test samples.

The static model according to Figure 1 was used for all groups of test samples. The samples were actually rotated by $90^{\circ}$ according to Figure 1 and they were therefore subjected to vertical force acting at the end of the elements (Figure 3a). The FPB were reinforced in the tensile diagonal area using SikaWrap-230C strips (Sika [9]) made from carbon high-strength fibre reinforced polymers of thickness $1.2 \mathrm{~mm}$. Strips with different widths (300 or $600 \mathrm{~mm}$ ) and of different boundary conditions were glued to the FPB.

The first group (G1) of three test samples was additionally reinforced with two CFRP diagonal strips (one in each FPB) of width $300 \mathrm{~mm}$ which were glued on the FPB using Sikadur-330 LVP. The strips were additionally glued to the timber frame (Figure 3a,b) to ensure the transmission of the force from FPB to the timber frame.

The second group (G2) of three test samples was additionally reinforced with two CFRP diagonal strips of width $600 \mathrm{~mm}$. The strips were glued on FPB and to the timber frame as in G1 (Figure 3b) to ensure the transmission of the force from FPB to the timber frame.

The third group (G3) of three test samples was additionally reinforced with two CFRP diagonal strips of width $300 \mathrm{~mm}$ as in G1 but they were not glued to the timber frame (Figure 3c).

Material properties for the test samples for all groups were the same (Table 1). Values for timber of quality $\mathrm{C} 22$ are taken from EN338 [10], the characteristics of fibre-plaster boards from Knauf [8] and for carbon strips Sika [9] data were used. 
a.)

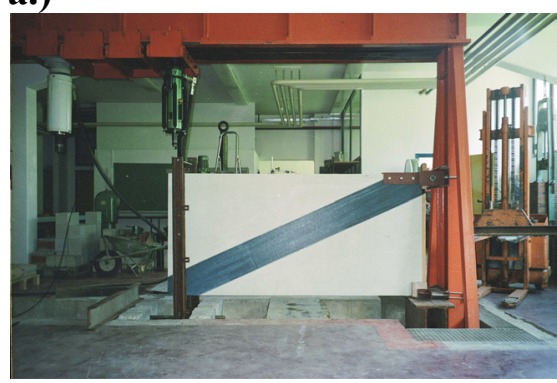

b.)

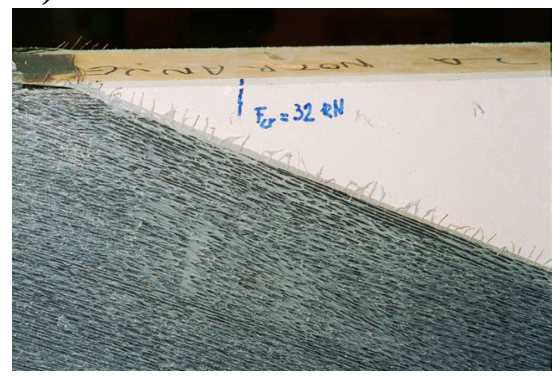

c.)

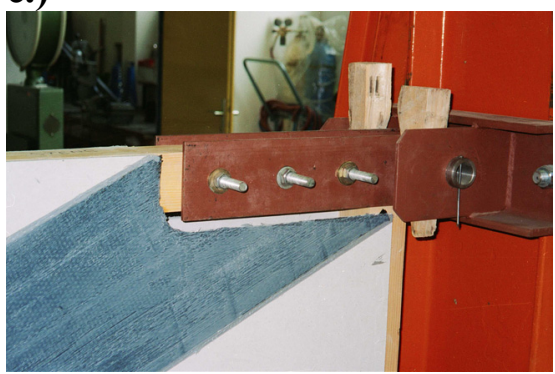

Figure 3: a.) G1; the static system, b.) G2; the CFRP strip is glued on the FPB and additionally to the timber frame, c.) G3; the CFRP strip is not glued to the timber frame.

Table 1: $\quad$ Properties of used materials.

\begin{tabular}{|l|c|c|c|c|c|c|}
\hline & $\begin{array}{c}\mathrm{E}_{0, \mathrm{~m}} \\
{\left[\mathrm{~N} / \mathrm{mm}^{2}\right]}\end{array}$ & $\begin{array}{c}\mathrm{G}_{\mathrm{m}} \\
{\left[\mathrm{N} / \mathrm{mm}^{2}\right]}\end{array}$ & $\begin{array}{c}\mathrm{f}_{\mathrm{m}, \mathrm{k}} \\
{\left[\mathrm{N} / \mathrm{mm}^{2}\right]}\end{array}$ & $\begin{array}{c}\mathrm{f}_{\mathrm{t}, 0, \mathrm{k}} \\
{\left[\mathrm{N} / \mathrm{mm}^{2}\right]}\end{array}$ & $\begin{array}{c}\mathrm{f}_{\mathrm{c}, 0, \mathrm{k}} \\
{\left[\mathrm{N} / \mathrm{mm}^{2}\right]}\end{array}$ & $\begin{array}{c}\rho_{\mathrm{m}} \\
{\left[\mathrm{kg} / \mathrm{m}^{3}\right]}\end{array}$ \\
\hline Timber & 10000 & 630 & 22 & 13 & 20 & 410 \\
\hline FPB & 3000 & 1200 & 4.0 & 2.5 & 20 & 1050 \\
\hline SikaWrap & 231000 & $/$ & $/$ & 4100 & $/$ & 1920 \\
\hline
\end{tabular}

\subsection{Test results and analysis}

The force forming the first crack $\left(\mathrm{F}_{\mathrm{cr}}\right)$ in the FPB, the crushing force $\left(\mathrm{F}_{\mathrm{u}}\right)$, the maximal cantilever bending deflection (w) under the acting force (F) and the slip $(\Delta)$ in the tensile area between the FPB and the timber frame were all measured. The measured values for the un-strengthened (UNS) test samples were taken from [6] and included for information and comparison only.

Average force forming the first crack $\left(\mathrm{F}_{\mathrm{cr}}\right)$ :

$$
\begin{array}{ll}
\text { G1: } F_{\mathrm{cr}, 1}=24.28 \mathrm{kN} & \mathrm{G} 3: \quad F_{\mathrm{cr}, 3}=35.90 \mathrm{kN} \\
\mathrm{G} 2: & F_{\mathrm{cr}, 2}=32.13 \mathrm{kN} \quad \text { UNS: } F_{\mathrm{cr}, \text { uns }}=17.67 \mathrm{kN}
\end{array}
$$


Average crushing force $\left(\mathrm{F}_{\mathrm{u}}\right)$ :

$$
\begin{aligned}
& \text { G1: } F_{\mathrm{u}, 1}=40.33 \mathrm{kN} \\
& \text { G3: } \quad \mathrm{F}_{\mathrm{u}, 3}=36.26 \mathrm{kN} \\
& \text { G2: } F_{\mathrm{u}, 2}=46.27 \mathrm{kN} \\
& \text { UNS: } F_{\mathrm{u}, \text { uns }}=26.02 \mathrm{kN}
\end{aligned}
$$

It is evident that the elastic resistance (force forming the first crack) essentially increased for all kinds of CFRP strengthened test samples, but mostly for samples G3, where the CFRP strips were not fixed to the timber frame. The CFRP influence was not so obvious at samples G1, where carbon strips of the same dimensions were additionally glued to the timber frame.

On the other hand, when comparing the measured results of the crushing force, a greater improvement can be noticed in the groups where the CFRP diagonals were glued to the timber frame. Compared to the un-strengthened test sample, the crushing force in samples G2 was increased by $78 \%$. In samples G3 the crushing force practically coincided with a force forming the first crack, so cracks hardly appeared at all, which is not a good solution to ensure better ductility, necessary for seismic design.

For further analysis it is important to present measured maximal cantilever deflections $(w)$ (Figure 4$)$ and slips $(\Delta)$ in the connecting area (Figure 5).

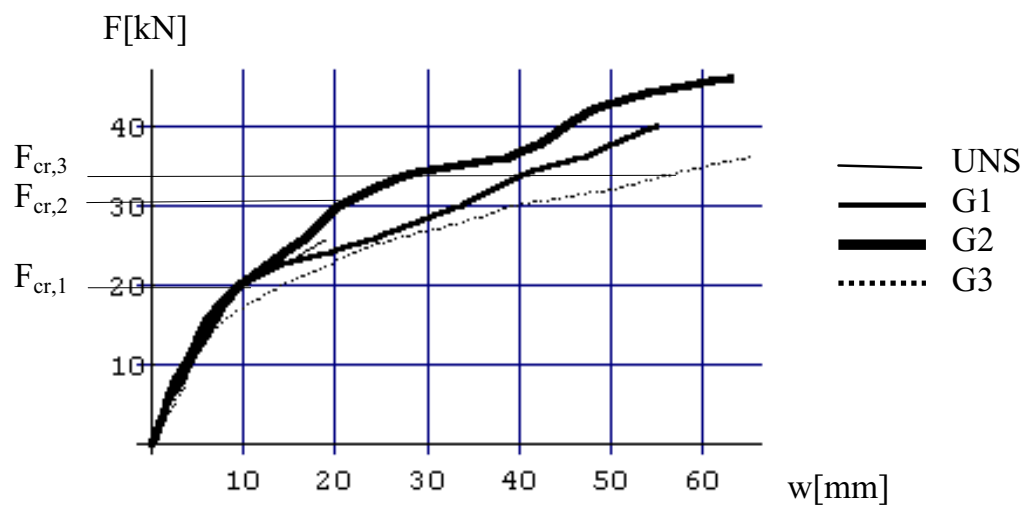

Figure 4: $\quad$ Measured average bending deflections (w).

Closer look at the graph in Figure 4 at $\mathrm{F}>17 \mathrm{kN}$ reveals an obvious difference in the behaviour of the test samples when the CFRP strips were glued to the timber frame (samples G1 and G2) or if they were not (samples G3). Beside the fact that samples G1 and especially G2 demonstrated higher load-carrying capacity than samples G3, it is also important to mention that samples G1 and G2 produced substantially smaller slip than samples G3, which never exceeded $1 \mathrm{~mm}$ at the first crack forming (Figure 5). Therefore it can be assumed that the yield point of the fasteners was not achieved before cracks appeared at all. Consequently, the walls tend to fail because of the crack forming in FPB. In this case of strengthening the ductility of the whole wall element (see Figure 5 for samples G1 and G2) practically coincides with the "ductility" of FPB, as proposed with $d_{1}$ and $d_{2}$ coefficients. 


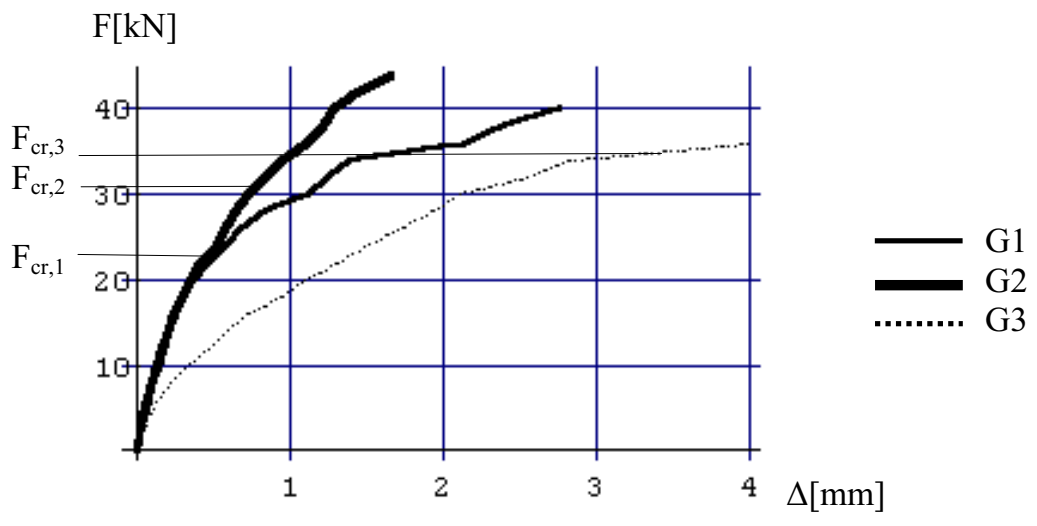

Figure 5: $\quad$ Measured average slips $(\Delta)$ in the connecting area.

In contrast, in G3 model, where the CFRP strips were unconnected to the timber frame, the slip $(\Delta)$ between the FPB and the timber frame was evidently higher than in samples G1 and G2, and exceeded $3 \mathrm{~mm}$ when the first crack in FPB appeared (Figure 5). The load-displacement relation (F- $\Delta$ ) of the fasteners was in this case at the force which produced first cracks almost completely plastic. Since the tensile strength of FPB is essentially improved, the walls tend to fail because of fastener yielding and therefore the "Lower bound plastic method" (EC5 Simplified Method A) can be used to determine the wall's load carrying capacity, (eqn 1).

\section{Conclusions}

As shown, there is practically no influence on the element stiffness of any reinforcement before cracks appeared in the un-strengthened FPB. However, after the first cracks in un-strengthened FPB appeared, the test samples demonstrated an important difference in behaviour dependant on the boundary conditions between the inserted CFRP strips and the timber frame.

If strips are glued to the timber frame the fasteners produced substantially smaller slip, which never exceeded $1 \mathrm{~mm}$ when the first cracks appeared. Therefore it can be assumed that the yield point of the fasteners is not achieved before cracks appeared at all and the elements tend to fail because cracks appear in the tensile area of FPB. Therefore, it is not recommended to use Eurocode 5 [2] simplified methods to predict the element resistance. Simple mathematical models with a fictive enlarged cross-section of FPB are proposed in [7].

In the case where the CFRP diagonals are unconnected to the timber frame, the slip between the FPB and the timber frame is evidently higher and the loaddisplacement relation of the fasteners is, after the cracks appeared, almost perfectly plastic. Since the tensile strength of FPB is with CFRP highly improved, the walls tend to fail because of fastener yielding, similar as at woodbased sheathing boards. Therefore the "Lower bound plastic method" can be used to determine the wall's load carrying capacity. 


\section{References}

[1] Faherty, K.F. \& Williamson, Wood Engineering and Construction Handbook, McGraw-Hill Publishing Company: 1989.

[2] CEN/TC 250/SC5 N173, Eurocode 5: Design of Timber Structures, Part 1-1 General rules and rules for buildings, Final draft prEN 1995-1-1, Brussels, 2003.

[3] Källsner, B., Panels as wind-bracing elements in timber-framed walls. Swedish Institute for Wood Technology Research, Report 56, Stockholm, 1984.

[4] Äkerlund, S., Simple calculation model for sheets on a timber frame, Bygg \& Teknik, No.1, 1984.

[5] Källsner, B. \& Lam, F., Diaphragms and shear walls. Holzbauwerke: Grundlagen, Entwicklungen, Ergänzungen nach Eurocode 5, Step 3, Fachverlag Holz: Düsseldorf, pp. 15/1-17, 1995.

[6] Dobrila, P. \& Premrov, M., Reinforcing methods for composite timber frame-fiberboard wall panels. Engineering Structures 25(11), pp. 13691376, 2003.

[7] Premrov, M. \& Dobrila, P., Approximate analytical solutions for diagonal reinforced timber-framed walls with fibre-plaster coating material. Construction and Building Materials, 18 (10), pp. 727-735.

[8] Knauf Gipsfaserplatten Vidivall/Vidifloor, 2002.

[9] Sika, Sicher bauen mit System. Technische Merkblätter. Ausgabe 5, 2003.

[10] European Committee for Standardization, EN 338:2003 E: Structural timber-Strength classes, Brussels, 2003. 